\title{
MONOGENIC MIMICS OF BEHÇET'S DISEASE IN THE YOUNG
}

C. Papadopoulou ${ }^{1 \dagger}$, E. Omoyinmi ${ }^{1 \dagger}$, A. Standing ${ }^{1}$, C. E. Pain ${ }^{2}$, C. Booth ${ }^{3}$, F. D’ Arco ${ }^{4}$, K. Gilmour $^{5}$, M. Buckland ${ }^{5}$, D. Eleftheriou ${ }^{1,6}$, P. A. Brogan ${ }^{1}$

1 Infection, Inflammation and Rheumatology Section, UCL Great Ormond Street Institute of Child Health, London, UK, and Great Ormond Street Hospital NHS Foundation Trust.

2 Department of Paediatric Rheumatology, Alder Hey Children's NHS Foundation Trust, Liverpool, UK

3 Infection, Immunity, Inflammation, Molecular and Cellular Immunology Section, UCL Great Ormond Street Institute of Child Health, London, United Kingdom

4 Neuroradiology, Great Ormond Street Hospital NHS Foundation Trust, London, United Kingdom

5 Immunology, Great Ormond Street Hospital NHS Foundation Trust, London, United Kingdom

6 Arthritis Research UK Centre for Adolescent Rheumatology, UCL, UCLH and GOSH, London, United Kingdom

${ }^{\dagger}$ These authors have contributed equally to this work

Corresponding author: Dr C Papadopoulou, Infection, Inflammation and Rheumatology, UCL Great Ormond Street Institute of Child Health, and Great Ormond Street Hospital NHS Foundation Trust, 30 Guilford Street, London WC1N 1EH

Tel: 020 79052392, Fax: 0044-2078138494,Email: sejjcp6@ucl.ac.uk 


\begin{abstract}
Objectives: Monogenic autoinflammatory disorders (AID) and primary immunodeficiencies can present early in life with features that may be mistaken for Behçet's disease (BD). We aimed to retrospectively describe the clinical and laboratory features of 11 paediatric cases referred for suspected BD who turned out to have an alternative, monogenic disease mimicking BD.
\end{abstract}

Methods: Retrospective, paediatric BD specialist multicentre case series. Next generation sequencing (NGS) or conventional candidate gene screening approaches were utilised, facilitated in some cases by functional assays.

Results: Eleven children referred with suspected BD underwent genetic screening because of atypical BD features, and/or presentation before age 5-years. Eight patients (73\%) were Caucasian; 2 were Pakistani; and 1 was Turkish; 55\% were female. A positive family history of $\mathrm{BD}$ was reported in $54 \%$ cases. The median age of disease onset was 0.6 (range 0.2-2.3) years. All had systemic inflammation and oral ulceration; 5/11 had genital ulceration; 3/11 had ocular involvement; and 9/11 had cutaneous manifestations. Nine/11 had known diseasecausing genetic mutations in: TNFAIP3 ( $\mathrm{n}=2), W D R 1(\mathrm{n}=2), N C F 1, A P 1 S 3, L Y N, M E F V$, and GLA. The remaining 2 cases each had novel variants in STAT1 and TNFRSF1A.

Conclusion: Rare monogenic diseases can mimic BD, particularly when presenting early in life. These observations are now informing a strategy to explore screening for genetic mimics of BD in a UK cohort of children and adults to better understand the proportion of UK BD patients who may in fact have an underlying monogenetic diagnosis.

Keywords: Behçet's Disease, child, autoinflammatory disease, next-generation sequencing, A20 haploinsufficiency, Fabry disease, Immunodeficiency, chronic mucocutaneous candidiasis disease

\title{
Key messages:
}

1. A wide range of monogenetic diseases may present with a BD-like phenotype.

2. Early disease onset, positive family history or atypical presentation constitute 'red flags' and should prompt genetic screening.

3. Next generation genetic sequencing should be considered as part of the diagnostic work up for young patients with suspected BD. 


\section{Main manuscript}

\section{Introduction}

Behçet's disease (BD) is a multi-systemic inflammatory variable vessel vasculitis affecting virtually any type of blood vessel but particularly veins, typically associated with recurrent oral and genital ulceration, ocular, and skin inflammation as cardinal features. Almost any organ can be affected, including the gastrointestinal, cardiovascular, renal, pulmonary, musculoskeletal and central nervous system (1). BD typically affects young adults 20 to 40 years of age but also affects children $(2,3)$ with onset under the age of 16 years in $4-26 \%$ (2, 4), and with median disease onset 4.9-12.3 years in different paediatric cohorts (3). The diagnosis is challenging since clinical presentation is heterogeneous and may vary by gender, ethnicity or age of disease onset (5). Clinical diagnostic criteria have therefore been devised but perform sub optimally, particularly in children at their first presentation (3).

The exact aetiology of $\mathrm{BD}$ is unknown. The prevailing hypothesis is that $\mathrm{BD}$ is the result of genetic susceptibility and environmental triggers, which subsequently cause dysregulation of the immune system. Several studies have demonstrated a multifactorial polygenic contribution (6). Genome-wide association (GWAS) and (to a lesser extent) next generation sequencing (NGS) studies have provided evidence for the role of genes involved in both innate and adaptive immunity (7). The human leukocyte antigen (HLA) loci, most importantly HLA-B*51 in the major histocompatibility complex (MHC) on chromosome 6, is considered the strongest known genetic risk factor for $\mathrm{BD}$, an association that has now been replicated in multiple populations $(8,9)$. $H L A-B * 51$ interacts with another susceptibility gene polymorphism, p.Arg725Gln in ERAP1, resulting in reduced peptide trimming activity, thus altering the peptides available for MHC class I binding (10), an example of epistatic genetic contribution to BD susceptibility. Associations between BD and other genetic variants around the MHC class I polypeptide-related sequence A (MICA) region have also been reported (9). Non-HLA susceptibility loci include: the intergenic region between IL23R and IL12RB2; IL10 (11); IL1A$I L 1 B, I R F 8$, and CEBPB-PTPN1 (9). An inherent and important limitation of GWAS, however, is that it focuses on common variants with allele frequencies greater than 5\%; rare genetic variants with allele frequencies less than $1 \%$ are excluded from association tests because of inadequate power to evaluate the effects in studies typically involving a few thousand individuals (10). This means that patients with monogenic diseases masquerading as BD will not be detected by GWAS. 
Next generation sequencing (NGS) is increasingly impacting on the clinical care of patients in virtually every aspect of medicine, including those with autoinflammatory or autoimmune diseases (AID). Recently, an AID with a familial BD-like phenotype has been reported in association with monoallelic mutation in TNFAIP3 resulting in haploinsufficiency of A20 protein, a regulator of NFKB activation (12). Other monogenic AID and some primary immunodeficiencies can also present early in life with Behçet-like symptoms and may be mistaken for BD. The aim of this study was therefore to describe the clinical and laboratory features of 11 cases referred to Great Ormond Street Hospital NHS Foundation Trust (GOSH) for suspected $\mathrm{BD}$, who ultimately turned out to have an alternative monogenetic diagnosis.

\section{Methods}

This was a retrospective case notes review collating anonymised clinical information obtained as part of routine clinical care. As such, patients were not required to provide written consent as per national and institutional ethical guidelines. Patients who underwent additional nextgeneration sequencing (i.e. if no genetic diagnosis was revealed by standard genetic testing) as part of their diagnostic work up did so with full written consent obtained and with full ethical approval from the National Research Ethics Service, Bloomsbury Committee, London (ethics number 08H071382).

A total of 11 patients were included, all referred to GOSH for advice and further management of suspected BD. Case notes were reviewed retrospectively, and pre-specified clinical and laboratory data were collected using a Microsoft Excel spreadsheet. Two BD definition scores were collated to explore their performance in this series: the ICBD criteria (supplementary table 1) with a score of 4 or more satisfying criteria for BD diagnosis (13); and the proposed new (2015) paediatric classification criteria (supplementary table 2), where 3/6 items are required to classify a patient as having paediatric BD (14).

Data analyses were descriptive, with numeric data summarised using median and interquartile range (IQR); as such no formal comparative statistical testing was required. Specific metrics scrutinised included the time to molecular diagnosis, calculated from the date of the first clinical review at GOSH to the date of confirmed genetic diagnosis (with functional study 
confirmation where this was necessary); in addition, the median age (and IQR) at the time of molecular diagnosis was calculated for this case series.

A combination of NGS or conventional candidate gene Sanger sequencing approaches were utilised to ascertain genetic diagnoses, facilitated in some cases by functional immunological or biochemical assays. NGS approaches included targeted exome sequencing (the "Vasculitis and Inflammation Panel", VIP) (15); or whole exome sequencing (WES). Targeted gene panel sequencing, bioinformatic analyses, and pathogenicity assessment of identified genetic variants were performed using standard methodologies, as previously described (15). The identified variants were individually assessed and classified into pathogenicity groups (Class 1: clearly not pathogenic; Class 2: unlikely to be pathogenic; Class 3: unknown significance; Class 4: likely to be pathogenic; Class 5; clearly pathogenic), according to the Association of Clinical Genetics Science Practice Guidelines (ACGS) 2013 guidelines (16). The level of evidence was assigned using the 2015 American College of Medical Genetics guidance (17). Variants detected using NGS were also confirmed using Sanger sequencing, to exclude false positives.

\section{Results}

\section{Demographics and clinical manifestations at presentation}

A total of 11 patients (6 females and 5 males) with a median age of 5 years (IQR 3-9 years) were identified. Eight patients (73\%) were Caucasian; 2 were Pakistani; and 1 was Turkish. The demographics and clinical features of all 11 cases are summarised in Table 1. Six out of the eleven had a family history of BD. Cases 4 and 5 were siblings from a consanguineous Pakistani kindred with suspected familial BD. Family trees for all 6 index cases with a positive family history are provided in Supplementary Figure 1.

The median age of disease onset was 0.6 (range 0.2-2.3) years, and the median age at first review at GOSH was 4.1 years (IQR 2.2-4.8 years). A genetic diagnosis was made a median of 4.5 (IQR 0.9-9.7) years after the first clinical visit at GOSH. All had suspected BD as the reason for referral to GOSH, and underwent further molecular testing because of symptom onset $<5$ years of age and/or incomplete or atypical BD features. All had systemic inflammation and oral ulceration. Episodes of fevers (affecting 9/11 cases) or systemic inflammation were 
recurrent rather than continuous, but typically non-periodic for this cohort. Detailed descriptions of these 11 patients are provided in Tables 1 and 2. Eight/11 patients (73\%) fulfilled ICBD criteria at the first presentation, compared with $6 / 11(55 \%)$ fulfilling the new Paediatric classification criteria (Table 2).

\section{Genetic testing}

Nine out of 11 cases were considered to have a definite monogenic cause that accounted for their phenotype. In the remaining 2 cases (cases 3 and 9), variants of uncertain clinical significance were identified as the suspected, but as yet unproven cause for the phenotype (Table 1). NGS was performed in 10 cases (gene panel in 7; WES in 3), with Sanger sequencing confirmation of identified class 5 variants and for familial segregation analyses. In the remaining patient (case 7) Sanger sequencing alone revealed the molecular diagnosis. More detailed descriptions of the phenotypes and associated genotypes classified according to pathogenicity (17) are provided, as follows.

\section{Clearly pathogenic variants (Class 5)}

Six/11 cases $(55 \%)$ had at least one class 5 (clearly pathogenic) variant (Table 1). The genetic variants harboured by these 6 cases fulfilled the pathogenicity criteria from literature evidence and pertinent functional laboratory immunological data supporting disease-genotype concordance (17).

A diagnosis of haploinsufficiency of A20 (HA20) was made in case 1 (Figure 1; Table 1). She was heterozygous for the highly penetrant loss-of-function nonsense mutation in TNFAIP3, (p.R271X), recently reported by Zhou et al as the cause of HA20 (18). The mother also had this mutation, and was being investigated for a milder, uncharacterised inflammatory phenotype (Supplementary Figure 1A).

We previously reported 2 Pakistani girls (Cases 4 and 5) born of consanguineous parents (pedigree B in Supplementary Figure 1) and diagnosed with familial BD beginning in the first weeks of life (19). Both had severe recurrent oral inflammation, which caused scarring 
and acquired microstomia in Case 4 (Figure 2). Both siblings were found to have a novel homozygous missense p.L293F mutation in the actin regulatory gene WDRl detected using WES, causing periodic fevers with immunodeficiency and thrombocytopenia (PFIT) (19).

Case 7 was referred with suspected BD with a history of pustules and erythematous rashes, recurrent oro-genital ulceration, gastrointestinal bleeding and high inflammatory markers from the age of 2.5 years (Figure 3A and 3B). Nitroblue tetrazolium (NBT) test revealed absent neutrophil respiratory burst, compatible with CGD (20); Sanger sequencing confirmed compound heterozygote mutation in NCF-1: c.75_76 del GT mutation in exon $2(21,22)$, and a splice site mutation c. $682+1 \mathrm{G}>\mathrm{C}$ mutation at the end of exon 7 , a site previously associated with CGD (23). Two further siblings were subsequently also diagnosed with CGD.

Case 8 was found to have the p.F4C mutation in AP1S3 which is associated with pustular psoriasis and impaired Toll-like Receptor 3 trafficking (24). She was commenced on infliximab $6 \mathrm{mg} / \mathrm{kg} 4$ weekly with a good response, later switching to adalimumab.

Case 11 was referred aged 15 years with fever of unknown origin, recurrent mouth ulcers suggestive of $\mathrm{BD}$, myalgia, fatigue, lymphadenopathy, colitis and skin rash reminiscent of panniculitis (but without histological confirmation), and weight loss. Investigations revealed raised inflammatory markers and microcytic anaemia $(\mathrm{Hb}=9.3 \mathrm{~g} / \mathrm{dL}, \mathrm{CRP}=46 \mathrm{mg} / \mathrm{L}, \mathrm{ESR}=100$ $\mathrm{mm} / \mathrm{hr}$ ). Upper and lower gastrointestinal tract endoscopies excluded inflammatory bowel disease. Selective visceral catheter arteriography angiography revealed subtle changes affecting the small intrarenal arteries suggestive of a vasculitic process, for which he was treated with corticosteroids and cyclophosphamide, followed by azathioprine maintenance immunosuppression. Despite that he went on to develop sagittal and bilateral cortical vein thromboses and bilateral parietal venous infarctions complicated by parenchymal haemorrhage on the left (Figure 4). At that point, cerebral venous thromboses complicating atypical BD was diagnosed, and treatment with infliximab was introduced. At the age of 25 years, genetic screening using our VIP gene panel revealed the heterozygous class 5 GLA p.G271S mutation causing Fabry disease (FD) (25), a lysosomal storage disease associated with cerebral vein thromboses (26). Assessment of leukocyte alpha-galactosidase A enzyme activity using fluorogenic method (27) revealed complete absence of enzyme activity ( $<1 \%$ of 
control), confirming the diagnosis and the mutation was confirmed by Sanger sequencing in the regional genetics laboratory. There were no other Class 4 or class 5 genetic mutations in any of the AID genes contained on VIP (supplementary Table 3). Alpha-galactosidase A enzyme replacement therapy has now been commenced.

\section{Likely pathogenic genetic variants (Class 4)}

Three/11 subjects (27\%) with likely pathogenic variants (class 4) are summarised in Table 1.

Case 2 presented with a history of recurrent panniculitis, abdominal pain, mouth ulcers and testicular pain associated with fever and elevated acute phase reactants. IL-1 blockade followed by tocilizumab provided only partial responses. Genetic testing revealed the p.Y508F variant in the tyrosine-protein kinase $L Y N$ gene, recently reported to cause a novel autoinflammatory syndrome with similar phenotype with our case, due to loss of the phosphorylation site (28). An animal model also confirms that this tyrosine residue at position 508 has important regulatory function, as mice with the p.Y508F mutation have enhanced enzymatic activity and present with haemolytic anaemia (29), lethal autoimmune glomerulonephritis and positive autoreactive antibodies (30).

We identified a novel STAT1 gain-of-function variant (p.L280W) in case 6, compatible with the diagnosis of chronic mucocutaneous candidiasis disease (CMCD), mimicking mucocutaneous Behçet's disease. Her symptoms began at the age of 7 months, with (initially) non-infective oral and genital ulcerative lesions (Figure 3C), associated with recurrent fevers. Treatment with colchicine, corticosteroids, azathioprine and adalimumab provided little symptomatic relief. Severe oral and oesophageal candidiasis emerged despite stopping all immunosuppression; she then developed recurrent chest infections, and episodes of paronychia requiring repeated courses of antibiotics. At the age of 6 years she developed acute adrenocortical insufficiency, confirmed on synacthen test, with absence of adrenal cortex autoantibodies. To explore the pathogenicity of this variant, a functional STAT1 phosphorylation assay was performed, adapted from an established STAT5 phosphorylation assay (31). We demonstrated increased STAT1 phosphorylation in response to IFNa stimulation in the lymphocytes of this patient compared to control (Supplementary Figure 2), providing strong supporting evidence for the pathogenicity of the identified p.L280W STAT1 
variant, and the diagnosis of CMCD. At the time of writing, treatment with a Janus Kinase inhibitor is being considered (32).

Case 10, with familial BD, was given a final diagnosis of HA20, also confirmed in the father. The paternal uncle and grandmother had also been previously diagnosed with severe BD (Supplementary Figure 1E). He and his father had a novel heterozygous mutation in exon 2 of TNFAIP3, c.292delA, predicted to cause a frameshift leading to a premature stop codon p.N98Tfs*25. Anakinra is being considered for this case at the time of writing.

\section{Variants of uncertain clinical significance (class 3)}

Two/11 patients had no class 5 or 4 variants but had notable class 3 variants in known AID genes. Case 3 first presented aged 3 years with severe recurrent oral ulceration from the age of 1 year but becoming progressively more severe over time. One episode required hospital admission due to a large ulcer involving his entire hard palate; and with punched-out skin ulcerations in his right axilla, with tender cervical lymphadenopathy and pyrexia. $\mathrm{He}$ subsequently developed recurrent scarring ulcers to his skin, and features of pathergy. His symptoms responded partially to oral corticosteroids and colchicine. VIP targeted gene panel screening revealed the p.K265R variant in exon 9 on the TNFSFR1A gene. Treatment with Anakinra has led to considerable improvement in his symptoms and improved quality of life.

Case 9, a Turkish male, presented with recurrent oral ulceration, and acneiform lesions from early in life. These symptoms responded well to colchicine. His mother had identical symptoms from early in life and had been diagnosed with BD (Supplementary Figure 1D). Genetic testing using our VIP targeted gene panel revealed a heterozygous p.I591T variant in $M E F V$, also present in the mother (confirmed with Sanger sequencing).

\section{Discussion}

In this retrospective study, we report eleven paediatric cases referred with suspected BD who ultimately turned out to have a monogenic disease mimicking BD. These cases had early onset 
of disease at median 0.6 years of age; and $54 \%$ had a positive family history, similar to previous reports of BD in the paediatric population (6). Although the clinical presentation was broad, all of the cases had recurrent aphthous stomatitis and evidence of systemic inflammation. At the time of first presentation to us, 8/11 (73\%) fulfilled the ICBD criteria for BD, while 6/11 (55\%) fulfilled the Paediatric Criteria for BD. Ten out of 11 were considered to have monogenic diseases of the immune system; the remaining case had FD, a lysosomal storage disease. Two were diagnosed with A20 haploinsufficiency. Both of them had recurrent oral ulceration and one also presented with genital ulceration, which are considered hallmarks of HA20 (33). One case was diagnosed with $L Y N$ associated autoinflammation. Regulation of immune cell function by the tyrosine kinase lyn has been previously demonstrated to be important for immune diseases (34); indeed dysregulation of lyn can lead to autoimmune diseases in mice, reminiscent of SLE, asthma and psoriasis; and recently a case with an earlyonset autoinflammatory phenotype has been reported in a patient with a de novo nonsense mutation in LYN (35). Other diagnoses included CGD, PFIT, CMCD and pustular psoriasis. For the remaining 2 cases, one had a novel variant in TNFRSF1A, and the other a monoallelic I591T variant in the $M E F V$ gene which segregated with disease in the mother.

Case 11 with FD was the only one out of our series that presented to us at an older age (15 years of age). Disease course was characterised by evidence of chronic inflammation, oral ulceration, rashes, lymphadenopathy and gastrointestinal involvement, compatible with autoinflammation. Undegraded substrates in lysosomes stimulate various pathogenic cascades that can ultimately cause autoinflammation, regardless of the specific lysosomal deposits (36). In FD, the autoinflammation is suggested to be primarily driven by glycolipid accumulation (Gb3 and lyso-Gb3), which is recognised as a danger signal. These lysosomal deposits may behave as damage associated molecular patterns (DAMPs), or cause DAMP production by injured cells, driving autoinflammation. Indeed, the addition of Gb3 to normal control cells induces apoptosis and cytokine secretion $(37,38)$. Thus, FD joins other emerging lysosomal storage diseases that recently have been associated with an autoinflammatory phenotype (39, 40). Cerebral vein thrombosis is well described in FD (41). Recently, Lenders et al (42) reported a high thromboembolic event rate for patients with FD that may be reduced by enzyme replacement therapy (42). Lysosomal accumulation of glycosphingolipids, primarily globotriaosylceramide (GL-3), in vascular endothelium may contribute mechanistically to the pathogenesis of thromboembolism in FD (43); other factors may include the presence of a concurrent prothrombotic state, abnormalities in cerebral blood flow velocity, and autonomic 
dysfunction (44). Thus, we highlight FD as an important mimic of BD which we suggest should be screened for, particularly for work up of suspected neuro-BD, and for BD patients with thrombo-embolic complications.

A disproportionately high prevalence of $M E F V$ mutations has been demonstrated in $\mathrm{BD}$ patients compared with the heathy population $(45,46)$. Moreover, the coexistence of both FMF and BD has been reported (47). A recent meta-analysis of 8 studies with a total of $2538 \mathrm{BD}$ patients and 2792 healthy controls demonstrated that M694V and M680I, two highly penetrant $M E F V$ mutations, were associated with BD; whereas E148Q, a low-penetrance pyrin mutation, was not linked to $\mathrm{BD}$ (46). A higher prevalence of $M E F V$ mutations has been observed in BD patients with vascular complications (45). The I591T MEFV mutation identified in case 9 was also found in his mother who had mucocutaneous features of BD. This variably penetrant MEFV mutation has been reported to cause FMF in both monoallelic and compound heterozygous states $(48,49)$. It is thus possible that case 9 , and his mother, do have a familial form of $\mathrm{BD}$ with this $M E F V$ variant contributing to the pathogenesis, as suggested for the M694V and M680I MEFV variants.

Most of the genetic studies done thus far in BD have been GWAS $(9,11)$. GWAS has markedly advanced our knowledge about the genetic determinants underlying the development and progression of BD, with the discovery of several polymorphisms. Although GWAS studies can serve as a powerful tool for elucidating associations between genes and traits, there are important limitations, particularly the aforementioned issue of excluding rare genetic variants. Additionally, population stratification, linkage disequilibrium, and DNA pooling can bias the results of GWAS. Therefore, GWAS studies of BD populations would not detect rare monogenic diseases masquerading as BD. That said, GWAS did suggest that polymorphisms (i.e. common variants) in TNFAIP3 could be important in BD (50) emphasising that GWAS and NGS studies can be complementary for understanding the genetic architecture of BD.

The highest level of analytic validity occurs when a variant in a gene has been previously associated with a particular disease, combined with pertinent functional assays supportive of pathogenicity. In our study, where available, we performed functional assays (i.e. NBT, STAT1 phosphorylation, and $\alpha$-galactosidase activity) to support our genetic findings. On the whole, however, rapid progress in genomic technologies has been faster than development of functional laboratory assays used to confirm or refute pathogenicity of genetic variants in 
routine clinical care, an area that requires ongoing effort as we move forwards in the post genomics era.

The main limitation of our study is the possibility of referral bias resulting in us receiving more atypical BD cases in our specialised paediatric BD clinical service (3). Secondly, we did not apply NGS genetic screening to all BD paediatric referrals we received at GOSH, mainly due to the practical fact that this approach has only relatively recently been introduced. Furthermore, we do not yet know how our findings will extrapolate to adult-onset BD. Therefore, our results do not yet allow us to provide firm guidance on which patients with BD should undergo genetic screening with NGS. Thus, whilst we await the results of a planned systematic NGS screening programme for UK BD patients, we suggest that patients with disease onset aged $<5$ years; with family history of BD; consanguinity; or atypical clinical course should be considered for NGS screening for monogenic disease. If a targeted gene panel approach rather than WES is used, clinicians should be aware of which genes are included to understand any potential limitations if the genetic screen is negative. Lastly, more extensive genetic screening with whole genome sequencing might in the future provide an even more accurate picture of the true frequency of monogenic diseases mimicking BD.

In conclusion, we highlight a range of monogenic mimics of paediatric BD and preliminarily suggest criteria for selecting patients for genetic screening. These data are now informing a strategy to begin to explore screening for genetic mimics of BD in a UK cohort of children and adults to better understand the proportion of UK BD patients who may have an underlying genetic diagnosis. This is important since treatment of monogenic BD mimics may differ significantly from standard BD treatment, as highlighted by our case series. Additionally, the determination of the underlying cause, whether treatable or not, has significance from the point of view of prognostication, genetic counselling, and in some instances avoidance of unnecessary and potentially harmful immunosuppression. 
Acknowledgments. All research at Great Ormond Street Hospital NHS Foundation Trust and UCL Great Ormond Street Institute of Child Health is made possible by the NIHR Great Ormond Street Hospital Biomedical Research Centre. The views expressed are those of the author(s) and not necessarily those of the NHS, the NIHR or the Department of Health. The authors wish to acknowledge Steve Hanson, Institute of Immunity and Transplantation, Royal Free Hospital NHS Foundation Trust, London for his contribution towards data acquisition.

Disclosure Statement. PB has received consultancy fees from Roche, SOBI, and UCB; DE has received consultancy fees from Roche and CB has received consultancy fees from Novimmune. The other authors declare no conflicts of interest.

Funding. PB has received institutional grants from Roche, SOBI, Novartis, Chemocentryx, and Novimmune; and is partly supported by GOSH Children's Charity. EO is funded in part from institutional grants from Rosetrees Trust and SOBI. DE has received institutional grants from Lilly, Pfizer and Roche and is also funded by Arthritis Research UK. CP is funded in part by ReMission. 


\section{References}

1. Calamia KT, Wilson FC, Icen M, Crowson CS, Gabriel SE, Kremers HM. Epidemiology and clinical characteristics of Behcet's disease in the US: a population-based study. Arthritis and rheumatism. 2009;61(5):600-4.

2. Karincaoglu Y, Borlu M, Toker SC, Akman A, Onder M, Gunasti S, et al. Demographic and clinical properties of juvenile-onset Behcet's disease: A controlled multicenter study. J Am Acad Dermatol. 2008;58(4):579-84.

3. Nanthapisal S, Klein NJ, Ambrose N, Eleftheriou D, Brogan PA. Paediatric Behcet's disease: a UK tertiary centre experience. Clin Rheumatol. 2016;35(10):2509-16.

4. Zouboulis CC, Kotter I, Djawari D, Kirch W, Kohl PK, Ochsendorf FR, et al. Epidemiological features of Adamantiades-Behcet's disease in Germany and in Europe. Yonsei Med J. 1997;38(6):411-22.

5. Kone-Paut I, Darce-Bello M, Shahram F, Gattorno M, Cimaz R, Ozen S, et al. Registries in rheumatological and musculoskeletal conditions. Paediatric Behcet's disease: an international cohort study of 110 patients. One-year follow-up data. Rheumatology (Oxford). 2011;50(1):184-8.

6. $\quad$ Kaya TI. Genetics of Behcet's Disease. Patholog Res Int. 2012;2012:912589.

7. Kone-Paut I. Behcet's disease in children, an overview. Pediatric rheumatology online journal. 2016;14(1):10.

8. Hughes T, Coit P, Adler A, Yilmaz V, Aksu K, Duzgun N, et al. Identification of multiple independent susceptibility loci in the HLA region in Behcet's disease. Nat Genet. 2013;45(3):319-24.

9. Takeuchi M, Mizuki N, Meguro A, Ombrello MJ, Kirino Y, Satorius C, et al. Dense genotyping of immune-related loci implicates host responses to microbial exposure in Behcet's disease susceptibility. Nat Genet. 2017;49(3):438-43.

10. Takeuchi M, Kastner DL, Remmers EF. The immunogenetics of Behcet's disease: A comprehensive review. J Autoimmun. 2015;64:137-48.

11. Kirino Y, Bertsias G, Ishigatsubo Y, Mizuki N, Tugal-Tutkun I, Seyahi E, et al. Genome-wide association analysis identifies new susceptibility loci for Behcet's disease and epistasis between HLA-B*51 and ERAP1. Nat Genet. 2013;45(2):202-7.

12. Zhou Q, Wang H, Schwartz DM, Stoffels M, Park YH, Zhang Y, et al. Loss-of-function mutations in TNFAIP3 leading to A20 haploinsufficiency cause an early-onset autoinflammatory disease. Nat Genet. 2016;48(1):67-73.

13. International Team for the Revision of the International Criteria for Behcet's D. The International Criteria for Behcet's Disease (ICBD): a collaborative study of 27 countries on the sensitivity and specificity of the new criteria. J Eur Acad Dermatol Venereol. 2014;28(3):33847.

14. Kone-Paut I, Shahram F, Darce-Bello M, Cantarini L, Cimaz R, Gattorno M, et al. Consensus classification criteria for paediatric Behcet's disease from a prospective observational cohort: PEDBD. Annals of the rheumatic diseases. 2016;75(6):958-64.

15. Omoyinmi E, Standing A, Keylock A, Price-Kuehne F, Melo Gomes S, Rowczenio D, et al. Clinical impact of a targeted next-generation sequencing gene panel for autoinflammation and vasculitis. PLoS One. 2017;12(7):e0181874.

16. Wallis Y, Payne S, McAnulty C, Bodmer D, Sistermans E, Robertson K, et al. Practice Guidelines for the Evaluation of Pathogenicity and the Reporting of Sequence Variants in Clinical Molecular Genetics. 2013. 
17. Richards S, Aziz N, Bale S, Bick D, Das S, Gastier-Foster J, et al. Standards and guidelines for the interpretation of sequence variants: a joint consensus recommendation of the American College of Medical Genetics and Genomics and the Association for Molecular Pathology. Genet Med. 2015;17(5):405-24.

18. Zhou Q, Wang H, Schwartz DM, Stoffels M, Park YH, Zhang Y, et al. Loss-of-function mutations in TNFAIP3 leading to A20 haploinsufficiency cause an early-onset autoinflammatory disease. Nat Genet. 2016;48(1):67-73.

19. Standing AS, Malinova D, Hong Y, Record J, Moulding D, Blundell MP, et al. Autoinflammatory periodic fever, immunodeficiency, and thrombocytopenia (PFIT) caused by mutation in actin-regulatory gene WDR1. J Exp Med. 2017;214(1):59-71.

20. de Vries E, Clinical Working Party of the European Society for I. Patient-centred screening for primary immunodeficiency: a multi-stage diagnostic protocol designed for nonimmunologists. Clin Exp Immunol. 2006;145(2):204-14.

21. Casimir CM, Bu-Ghanim HN, Rodaway AR, Bentley DL, Rowe P, Segal AW. Autosomal recessive chronic granulomatous disease caused by deletion at a dinucleotide repeat. Proc Natl Acad Sci U S A. 1991;88(7):2753-7.

22. Wolach B, Gavrieli R, de Boer M, van Leeuwen K, Berger-Achituv S, Stauber T, et al. Chronic granulomatous disease: Clinical, functional, molecular, and genetic studies. The Israeli experience with 84 patients. Am J Hematol. 2017;92(1):28-36.

23. Jakobsen MA, Katzenstein TL, Valerius NH, Roos D, Fisker N, Mogensen TH, et al. Genetical analysis of all Danish patients diagnosed with chronic granulomatous disease. Scand J Immunol. 2012;76(5):505-11.

24. Setta-Kaffetzi N, Simpson MA, Navarini AA, Patel VM, Lu HC, Allen MH, et al. AP1S3 mutations are associated with pustular psoriasis and impaired Toll-like receptor 3 trafficking. Am J Hum Genet. 2014;94(5):790-7.

25. Shabbeer J, Yasuda M, Benson SD, Desnick RJ. Fabry disease: identification of 50 novel alpha-galactosidase A mutations causing the classic phenotype and three-dimensional structural analysis of 29 missense mutations. Hum Genomics. 2006;2(5):297-309.

26. Feldt-Rasmussen U. Fabry disease and early stroke. Stroke Res Treat. 2011;2011:615218.

27. Gal A, Hughes DA, Winchester B. Toward a consensus in the laboratory diagnostics of Fabry disease - recommendations of a European expert group. J Inherit Metab Dis. 2011;34(2):509-14.

28. De Jesus AA, Montealegre G, Liu Y, Marrero B, Kuehn H, Calvo K, et al. A de novo nonsense mutation in the tyrosine kinase lyn in a patient with an early onset autoinflammatory phenotype. Pediatric rheumatology online journal. 2014;12(Suppl 1):O25-O.

29. Slavova-Azmanova NS, Kucera N, Satiaputra J, Stone L, Magno A, Maxwell MJ, et al. Gain-of-function Lyn induces anemia: appropriate Lyn activity is essential for normal erythropoiesis and Epo receptor signaling. Blood. 2013;122(2):262-71.

30. Hibbs ML, Harder KW, Armes J, Kountouri N, Quilici C, Casagranda F, et al. Sustained activation of Lyn tyrosine kinase in vivo leads to autoimmunity. $\mathrm{J}$ Exp Med. 2002;196(12):1593-604.

31. Walshe D, Gaspar HB, Thrasher AJ, Cale CM, Gilmour KC. Signal transducer and activator of transcription 5 tyrosine phosphorylation for the diagnosis and monitoring of patients with severe combined immunodeficiency. J Allergy Clin Immunol. 2009;123(2):5058.

32. Higgins E, Al Shehri T, McAleer MA, Conlon N, Feighery C, Lilic D, et al. Use of ruxolitinib to successfully treat chronic mucocutaneous candidiasis caused by gain-of-function signal transducer and activator of transcription 1 (STAT1) mutation. J Allergy Clin Immunol. 2015;135(2):551-3. 
33. Aeschlimann FA, Batu ED, Canna SW, Go E, Gul A, Hoffmann P, et al. A20 haploinsufficiency (HA20): clinical phenotypes and disease course of patients with a newly recognised NF-kB-mediated autoinflammatory disease. Annals of the rheumatic diseases. 2018.

34. Ingley E. Functions of the Lyn tyrosine kinase in health and disease. Cell Commun Signal. 2012;10(1):21.

35. Almeida De Jesus A, Montealegre G, Liu Y, Marrero B, Kuehn H, Calvo K, et al. A de novo nonsense mutation in the tyrosine kinase lyn in a patient with an early onset autoinflammatory phenotype. Pediatr Rheumatol Online J. 2014;12(Suppl 1); .

36. Platt FM, Boland B, van der Spoel AC. The cell biology of disease: lysosomal storage disorders: the cellular impact of lysosomal dysfunction. J Cell Biol. 2012;199(5):723-34.

37. De Francesco PN, Mucci JM, Ceci R, Fossati CA, Rozenfeld PA. Fabry disease peripheral blood immune cells release inflammatory cytokines: role of globotriaosylceramide. Mol Genet Metab. 2013;109(1):93-9.

38. Rozenfeld P, Feriozzi S. Contribution of inflammatory pathways to Fabry disease pathogenesis. Mol Genet Metab. 2017;122(3):19-27.

39. Senniappan S, Hughes M, Shah P, Shah V, Kaski JP, Brogan P, et al. Pigmentary hypertrichosis and non-autoimmune insulin-dependent diabetes mellitus (PHID) syndrome is associated with severe chronic inflammation and cardiomyopathy, and represents a new monogenic autoinflammatory syndrome. J Pediatr Endocrinol Metab. 2013;26(9-10):877-82.

40. Rafiq NK, Hussain K, Brogan PA. Tocilizumab for the Treatment of SLC29A3 Mutation Positive PHID Syndrome. Pediatrics. 2017;140(5).

41. Utsumi K, Ueda K, Watanabe M, Sakamaki M, Arii K, Yamazaki M, et al. Thrombosis in Japanese patients with Fabry disease. J Neurol Sci. 2009;283(1-2):83-5.

42. Lenders M, Karabul N, Duning T, Schmitz B, Schelleckes M, Mesters R, et al. Thromboembolic events in Fabry disease and the impact of factor V Leiden. Neurology. 2015;84(10):1009-16.

43. Zarate YA, Hopkin RJ. Fabry's disease. Lancet. 2008;372(9647):1427-35.

44. Sims K, Politei J, Banikazemi M, Lee P. Stroke in Fabry disease frequently occurs before diagnosis and in the absence of other clinical events: natural history data from the Fabry Registry. Stroke. 2009;40(3):788-94.

45. Atagunduz P, Ergun T, Direskeneli H. MEFV mutations are increased in Behcet's disease (BD) and are associated with vascular involvement. Clin Exp Rheumatol. 2003;21(4 Suppl 30):S35-7.

46. Wu Z, Zhang S, Li J, Chen S, Li P, Sun F, et al. Association between MEFV Mutations M694V and M680I and Behcet's Disease: A Meta-Analysis. PLoS One. 2015;10(7):e0132704. 47. Zerkaoui M, Laarabi FZ, Ajhoun Y, Chkirate B, Sefiani A. A novel single variant in the MEFV gene causing Mediterranean fever and Behcet's disease: a case report. J Med Case Rep. 2018;12(1):53.

48. Aldea A, Casademont J, Arostegui JI, Rius J, Maso M, Vives J, et al. I591T MEFV mutation in a Spanish kindred: is it a mild mutation, a benign polymorphism, or a variant influenced by another modifier? Hum Mutat. 2002;20(2):148-50.

49. Fisher BA, Lachmann HJ, Rowczenio D, Goodman HJ, Bhalara S, Hawkins PN. Colchicine responsive periodic fever syndrome associated with pyrin I591T. Annals of the rheumatic diseases. 2005;64(9):1384-5.

50. Li H, Liu Q, Hou S, Du L, Zhou Q, Zhou Y, et al. TNFAIP3 gene polymorphisms confer risk for Behcet's disease in a Chinese Han population. Hum Genet. 2013;132(3):293300 . 

Table 1. Clinical features and genetic variants identified in patients with a Behçet's-like presentation

\begin{tabular}{|c|c|c|c|c|c|c|c|c|c|c|c|c|}
\hline $\begin{array}{c}\text { Case } \\
\text { No }\end{array}$ & $\begin{array}{l}\text { Ethni- } \\
\text { city }\end{array}$ & $\begin{array}{l}\text { Con } \\
\text { san }\end{array}$ & Sex & $\begin{array}{l}\text { Age } \\
* * \\
(y r s)\end{array}$ & Gene & $\begin{array}{l}\text { Nucleotide } \\
\text { change* }\end{array}$ & $\begin{array}{l}\text { Amino acid } \\
\text { change* }\end{array}$ & $\begin{array}{c}\text { Predicted } \\
\text { pathogenic } \\
\text {-ity } \Phi\end{array}$ & $\begin{array}{l}\text { Zy- } \\
\text { gosity }\end{array}$ & $\begin{array}{l}\text { Variant } \\
\text { classify } \\
\text {-cation }\end{array}$ & $\begin{array}{c}\text { Clinical features, } \\
\text { and treatment }\end{array}$ & $\begin{array}{c}\text { Final diagnosis and } \\
\text { outcome }\end{array}$ \\
\hline 1 & Cauc & $\mathrm{N}$ & $\mathrm{F}$ & 5 & TNFAIP3 & $811 C>T$ & R271X & T/-/D & Het & 5 & $\begin{array}{c}\text { Uveitis, mouth } \\
\text { ulcers, vasculitic } \\
\text { rash, lupus nephritis } \\
\text { class III and IV } \\
\text { Intermittent high } \\
\text { ESR, normal } \\
\text { CRP/SAA } \\
\text { Hydroxychloroquin } \\
\text { e, azathioprine, } \\
\text { mycophenolate } \\
\text { mofetil } \\
\text { unresponsive }\end{array}$ & $\begin{array}{c}\text { HA20; genetic } \\
\text { counselling; alive, } \\
\text { and being } \\
\text { considered for IL-1 } \\
\text { blockade }\end{array}$ \\
\hline 2 & Cauc & $\mathrm{N}$ & $\mathrm{M}$ & 15 & $L Y N$ & $1523 \mathrm{~A}>\mathrm{T}$ & Y508F & $\mathrm{D} / \mathrm{D} / \mathrm{D}$ & Het & 4 & $\begin{array}{l}\text { Recurrent but non- } \\
\text { periodic fevers, } \\
\text { panniculitis, } \\
\text { abdominal pain, }\end{array}$ & $\begin{array}{c}\text { LYN associated } \\
\text { AID; alive }\end{array}$ \\
\hline
\end{tabular}




\begin{tabular}{|c|c|c|c|c|c|c|c|c|c|c|c|c|}
\hline & & & & & & & & & & & $\begin{array}{c}\text { headaches, } \\
\text { conjunctivitis, } \\
\text { arthralgia, mouth } \\
\text { ulcers, } \\
\text { intermittently } \\
\text { elevated CRP/SAA } \\
\text { Anakinra and } \\
\text { tocilizumab } \\
\text { unresponsive, } \\
\text { Colchicine partial } \\
\text { response }\end{array}$ & \\
\hline 3 & Cauc & $\mathrm{N}$ & $\mathrm{M}$ & 5 & TNFRSF1A & $794 A>G$ & K265R & $\mathrm{B} /-/ \mathrm{N}$ & Het & 3 & $\begin{array}{c}\text { Intermittent (but } \\
\text { typically non- } \\
\text { periodic) systemic } \\
\text { inflammation, } \\
\text { recurrent oral } \\
\text { ulceration, pathergy, } \\
\text { poor wound healing, } \\
\text { chronic vocal cord } \\
\text { inflammation; }\end{array}$ & $\begin{array}{c}\text { Undefined } \\
\text { autoinflammatory } \\
\text { disorder (carrying a } \\
\text { variant of uncertain } \\
\text { clinical significance in } \\
\text { TNFRSF1A; } \\
\text { alive }\end{array}$ \\
\hline
\end{tabular}




\begin{tabular}{|c|c|c|c|c|c|c|c|c|c|c|c|c|}
\hline & & & & & & & & & & & $\begin{array}{c}\text { Intermittent high } \\
\text { ESR/CRP/SAA; } \\
\text { negative workup for } \\
\text { immunodeficiency; } \\
\text { good response to } \\
\text { anakinra }\end{array}$ & \\
\hline 4 & Pakist & $\mathrm{Y}$ & $\mathrm{F}$ & 3 & WDRl & $877 \mathrm{C}>\mathrm{T}$ & L293F & $\mathrm{P} / \mathrm{D} / \mathrm{D}$ & Hom & 5 & $\begin{array}{l}\text { Intermittent but } \\
\text { non-periodic } \\
\text { systemic } \\
\text { inflammation, } \\
\text { recurrent orogenital } \\
\text { ulceration, arthritis } \\
\text { and fevers, recurrent } \\
\text { upper respiratory } \\
\text { tract infections, } \\
\text { negative work up } \\
\text { for } \\
\text { immunodeficiency, } \\
\text { intermittent high } \\
\text { ESR/CRP; } \\
\text { underwent }\end{array}$ & $\begin{array}{l}\text { PFIT; alive and off } \\
\text { all } \\
\text { immunosuppression } \\
\text { post allo- HSCT } 6 \\
\text { years }\end{array}$ \\
\hline
\end{tabular}




\begin{tabular}{|c|c|c|c|c|c|c|c|c|c|c|c|c|}
\hline & & & & & & & & & & & $\begin{array}{c}\text { allogeneic HSCT in } \\
2013 \text { with curative } \\
\text { outcome }\end{array}$ & \\
\hline 5 & Pakist & $\mathrm{Y}$ & $\mathrm{F}$ & 12 & WDR1 & $877 C>T$ & L293F & $\mathrm{P} / \mathrm{D} / \mathrm{D}$ & Hom & 5 & $\begin{array}{c}\text { Recurrent (non- } \\
\text { periodic) fever, } \\
\text { orogenital } \\
\text { ulceration, uveitis, } \\
\text { thrombocytopenia, } \\
\text { pyoderma } \\
\text { gangrenosum-like } \\
\text { rash, arthritis, high } \\
\text { ESR, CRP, SAA, } \\
\text { initially good } \\
\text { response to } \\
\text { anakinra; death } \\
\text { from sterile } \\
\text { inflammation and } \\
\text { multi-organ failure } \\
\text { age } 14 \text { years }\end{array}$ & $\begin{array}{c}\text { PFIT; died age } 14 \\
\text { years }\end{array}$ \\
\hline 6 & Cauc & $\mathrm{N}$ & $\mathrm{F}$ & 3 & STAT1 & $839 \mathrm{~T}>\mathrm{G}$ & L280W & $-/ \mathrm{D} / \mathrm{D}$ & Het & 4 & $\begin{array}{l}\text { Recurrent (non- } \\
\text { periodic) fever with }\end{array}$ & CMCD; alive \\
\hline
\end{tabular}




\begin{tabular}{|c|c|c|c|c|c|c|c|c|c|c|c|c|}
\hline & & & & & & & & & & & $\begin{array}{c}\text { orogenital } \\
\text { ulceration, recurrent } \\
\text { chest infections, } \alpha- \\
\text { antitrypsin } \\
\text { deficiency with } \\
\text { elevated } \\
\text { transaminases }\end{array}$ & \\
\hline 7 & Cauc & $\mathrm{N}$ & $\mathrm{F}$ & 3 & $\begin{array}{l}N C F 1 \\
N C F 1\end{array}$ & $\begin{array}{c}682 \mathrm{G}>\mathrm{C} \\
75 \_76 \mathrm{del} \\
\text { GT }\end{array}$ & $\begin{array}{c}\text { G228R } \\
\text { Y26Hfs*26 }\end{array}$ & $\begin{array}{l}\mathrm{n} / \mathrm{a} \\
\mathrm{n} / \mathrm{a}\end{array}$ & $\begin{array}{l}\text { Hom } \\
\text { Het }\end{array}$ & 5 & $\begin{array}{c}\text { Recurrent fever } \\
\text { (periodicity not } \\
\text { documented); } \\
\text { Pustules } \\
\text { erythematous rash, } \\
\text { orogenital } \\
\text { ulceration, PR } \\
\text { bleeding, } \\
\text { high ESR/CRP } \\
\text { allogeneic HSCT } \\
\text { age } 5 \text { years }\end{array}$ & $\begin{array}{c}\text { Autosomal } \\
\text { recessive CGD; } \\
\text { alive } 3 \text { years post } \\
\text { HSCT }\end{array}$ \\
\hline 8 & Cauc & $\mathrm{N}$ & $\mathrm{F}$ & 4 & $A P 1 S 3$ & $11 \mathrm{~T}>\mathrm{G}$ & $\mathrm{F} 4 \mathrm{C}$ & $\mathrm{D} / \mathrm{D} / \mathrm{D}$ & Het & 5 & $\begin{array}{l}\text { Recurrent but non- } \\
\text { periodic fever, } \\
\text { mouth ulcers, facial }\end{array}$ & $\begin{array}{c}\text { Pustular Psoriasis; } \\
\text { alive }\end{array}$ \\
\hline
\end{tabular}




\begin{tabular}{|c|c|c|c|c|c|c|c|c|c|c|c|c|}
\hline & & & & & & & & & & & $\begin{array}{c}\text { and lip swelling, } \\
\text { lethargy, pustular } \\
\text { skin lesions, } \\
\text { myalgia and } \\
\text { arthralgia; } \\
\text { Infliximab } \\
\text { switched to } \\
\text { Adalimumab with } \\
\text { good response }\end{array}$ & \\
\hline 9 & Turkish & $\mathrm{N}$ & $\mathrm{m}$ & 6 & $M E F V$ & $1772 \mathrm{~T}>\mathrm{C}$ & I591T & $\mathrm{B} / \mathrm{T} / \mathrm{N}$ & Het & 3 & $\begin{array}{c}\text { No fevers but } \\
\text { recurrent mouth } \\
\text { ulcers, abdominal } \\
\text { pain, pustular rash, } \\
\text { PR bleeding; partial } \\
\text { response to } \\
\text { colchicine }\end{array}$ & $\begin{array}{c}\text { Undefined } \\
\text { autoinflammatory } \\
\text { disorder with } \\
\text { variant of uncertain } \\
\text { significance in } \\
\text { MEFV; alive }\end{array}$ \\
\hline 10 & Cauc & $\mathrm{N}$ & $\mathrm{M}$ & 2 & TNFAIP3 & c.292delA & p.N98Tfs 25 & & Het & 4 & $\begin{array}{l}\text { No fevers; recurrent } \\
\text { mouth ulcers, penile } \\
\text { ulceration; no } \\
\text { treatment as yet }\end{array}$ & HA20; alive \\
\hline
\end{tabular}




\begin{tabular}{|c|c|c|c|c|c|c|c|c|c|c|c|c|}
\hline 11 & Cauc & $\mathrm{N}$ & $\mathrm{M}$ & 25 & $G L A$ & c.G811A & p.G271S & $\mathrm{D} / \mathrm{D} / \mathrm{D}$ & Hom & 5 & $\begin{array}{c}\text { Recurrent but non- } \\
\text { periodic fevers, oral } \\
\text { and oesophageal } \\
\text { ulceration, } \\
\text { panniculitis, } \\
\text { systemic } \\
\text { inflammation, mild } \\
\text { terminal ileal } \\
\text { ulceration, sagittal } \\
\text { vein thrombosis and } \\
\text { secondary epilepsy } \\
\text { high ESR/CRP } \\
\text { Absence of } \\
\text { leukocyte alpha- } \\
\text { galactosidase } \\
\text { activity (checked } \\
\text { after Fabry } \\
\text { genotype } \\
\text { ascertained); } \\
\text { Treated (prior to } \\
\text { Fabry diagnosis) }\end{array}$ & $\begin{array}{c}\text { Fabry disease; } \\
\text { commencing } \\
\text { enzyme } \\
\text { replacement } \\
\text { therapy }\end{array}$ \\
\hline
\end{tabular}




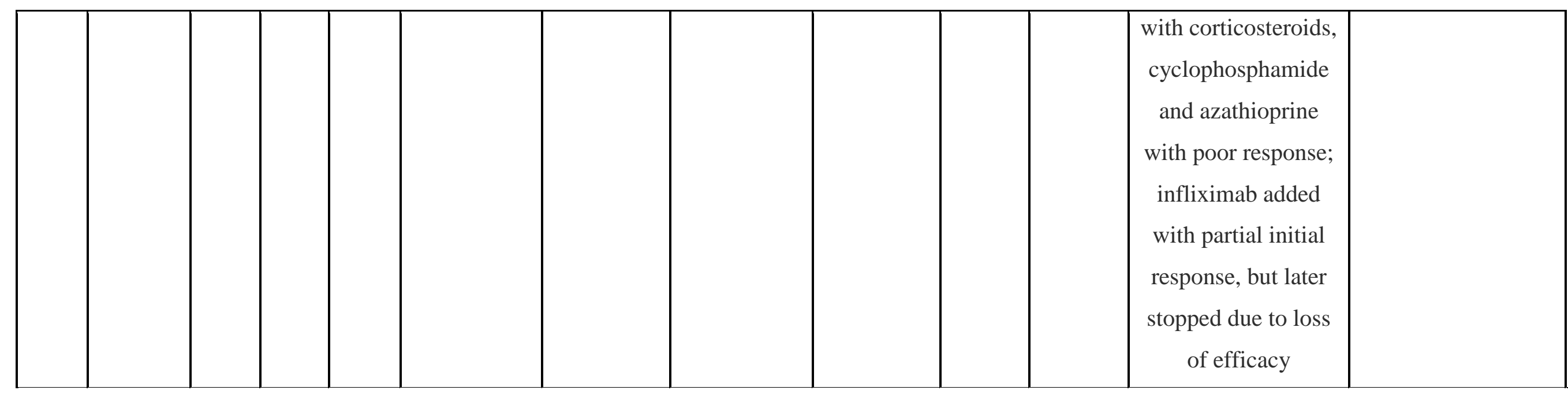

*Since each gene may have multiple splicing isoforms, the variants were annotated according to the RefSeq transcript in supplementary table S3

**Age at the time of this study.

TPrediction (polyphen2/SIFT/MutationTaster); $\mathrm{B}=$ Benign, $\mathrm{D}=$ damaging or deleterious, $\mathrm{P}=$ probably damaging, $\mathrm{T}=$ tolerated, $\mathrm{n}=$ neutral, $\mathrm{A}=$ disease causing automatic for MutationTaster.

Abbreviations: Cauc $=$ caucasian, Pakist $=$ Pakistani, $\mathrm{CRP}=\mathrm{C}$-reactive protein, $\mathrm{SAA}=$ Serum amyloid $\mathrm{A}, \mathrm{ESR}=$ erythrocyte sedimentation rate, $\mathrm{MTX}=\mathrm{Methotrexate}, \mathrm{DMARDS}=$ Disease-modifying anti-rheumatic drugs, AID $=$ autoinflammatory disease, $\mathrm{CMCD}=$ Chronic Mucocutaneous Candidiasis Disease, $\mathrm{CGD}=$ Chronic granulomatous disease, $\mathrm{HA} 20=\mathrm{A} 20$ haploinsufficiency, PFIT $=$ Periodic fevers, immunodeficiency, and thrombocytopenia, TRAPS $=$ TNF receptor-associated autoinflammatory syndrome, Consan $=$ Consanguinity $(\mathrm{Y}=$ yes, $\mathrm{N}$ $=$ no, $\mathrm{U}=$ unknown $), \mathrm{Sex}(\mathrm{F}=$ female, $\mathrm{M}=$ male). $\mathrm{HSCT}=$ Haematopoietic stem cell transplantation, $\mathrm{CS}=$ corticosteroid (including pulses of intravenous methylprednisolone or oral prednisolone); GI = gastrointestinal, PR = per-rectal, FMF = Familial Mediterranean Fever, IL1 = Interleukin 1 
Table 2. Comparison of the scores for the International Criteria for Behçet's Disease (ICBD) and Paediatric Criteria for Behçet's Disease (2015)

\begin{tabular}{|c|c|c|c|c|c|c|c|c|c|}
\hline Case & $\begin{array}{c}\text { Oral } \\
\text { aphthosis }\end{array}$ & $\begin{array}{c}\text { Genital } \\
\text { aphthosis }\end{array}$ & $\begin{array}{c}\text { Ocular } \\
\text { involvement }\end{array}$ & $\begin{array}{c}\text { Vascular } \\
\text { signs }\end{array}$ & $\begin{array}{c}\text { Neurological } \\
\text { signs }\end{array}$ & $\begin{array}{c}\text { Skin } \\
\text { involvement }\end{array}$ & $\begin{array}{c}\text { Pathergy } \\
\text { Test (+) }\end{array}$ & $\begin{array}{c}\text { ICBD } \\
\text { score } \\
\text { fulfilled } \\
(\mathrm{Y} / \mathrm{N})\end{array}$ & $\begin{array}{c}\text { Paediatric } \\
\text { BD } \\
\text { Criteria } \\
\text { fulfilled } \\
(\mathrm{Y} / \mathrm{N})\end{array}$ \\
\hline 1 & 2 & 0 & 2 & 0 & 0 & 1 & 0 & $\bar{Y}$ & $\bar{Y}$ \\
\hline 2 & 2 & 0 & 2 & 0 & 0 & 1 & 0 & $\bar{Y}$ & $\bar{Y}$ \\
\hline 3 & 2 & 0 & 0 & 0 & 0 & 1 & 1 & $\bar{Y}$ & $\mathrm{~N}$ \\
\hline 4 & 2 & 2 & 0 & 0 & 0 & 0 & 0 & $\mathrm{~N}$ & $\mathrm{~N}$ \\
\hline 5 & 2 & 2 & 2 & 0 & 0 & 1 & 0 & $\mathrm{Y}$ & $\mathrm{Y}$ \\
\hline 6 & 2 & 2 & 0 & 0 & 0 & 1 & 0 & $\bar{Y}$ & $\bar{Y}$ \\
\hline 7 & 2 & 2 & 0 & 0 & 0 & 1 & 0 & $\mathrm{Y}$ & $Y$ \\
\hline 8 & 2 & $\overline{0}$ & $\overline{0}$ & $\overline{0}$ & $\overline{0}$ & 1 & $\overline{0}$ & $\mathrm{~N}$ & $\mathrm{~N}$ \\
\hline
\end{tabular}




\begin{tabular}{|c|c|c|c|c|c|c|c|c|c|}
\hline 9 & 2 & 0 & 0 & 0 & 0 & 1 & 0 & $\mathrm{~N}$ & $\bar{N}$ \\
\hline 10 & 2 & 2 & 0 & 0 & 0 & 0 & 0 & $\mathrm{Y}$ & $\mathrm{N}$ \\
\hline 11 & 2 & 0 & 0 & 1 & 1 & 1 & 0 & $\mathrm{Y}$ & $Y$ \\
\hline
\end{tabular}


Figure 1. Case 1: vasculitic rashes of feet and hand (A, B).

A

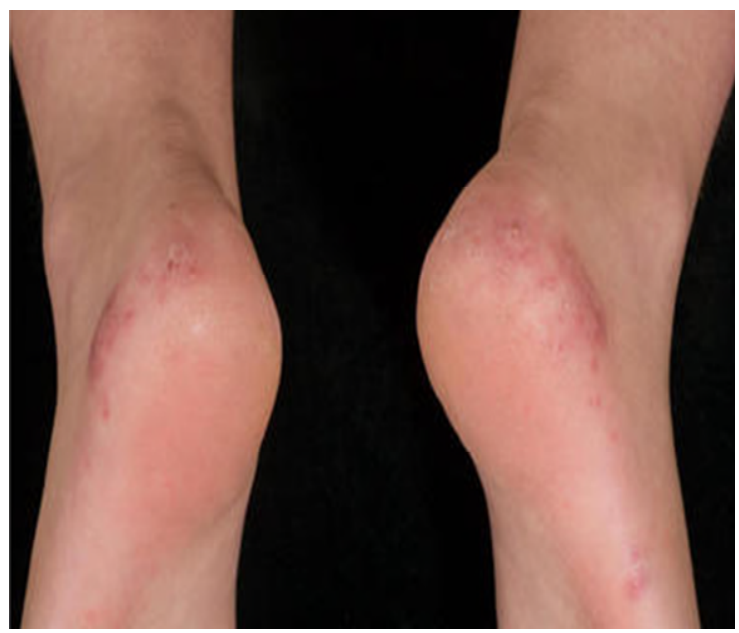

B

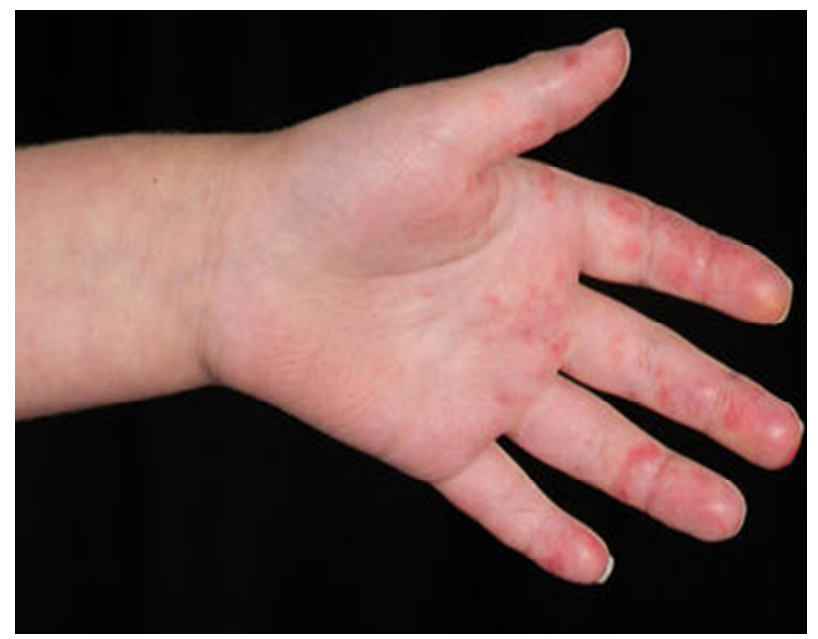


Figure 2. Acquired microstomia (A) in case 6 aged 12 years and 10 months, the consequence of recurrent sterile oral inflammatory episodes. At 13 years of age, she developed a severe necrotizing cellulitis of the neck caused by Streptococcus pneumoniae (B).

A

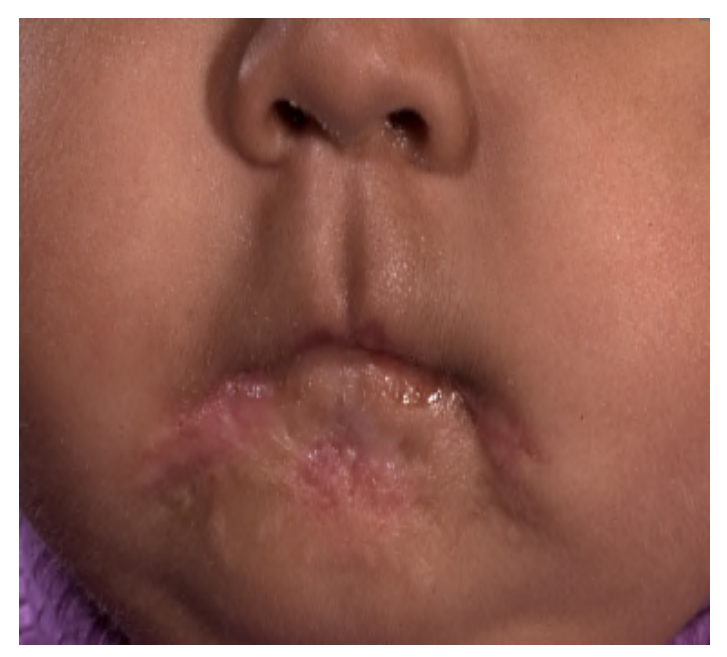

B

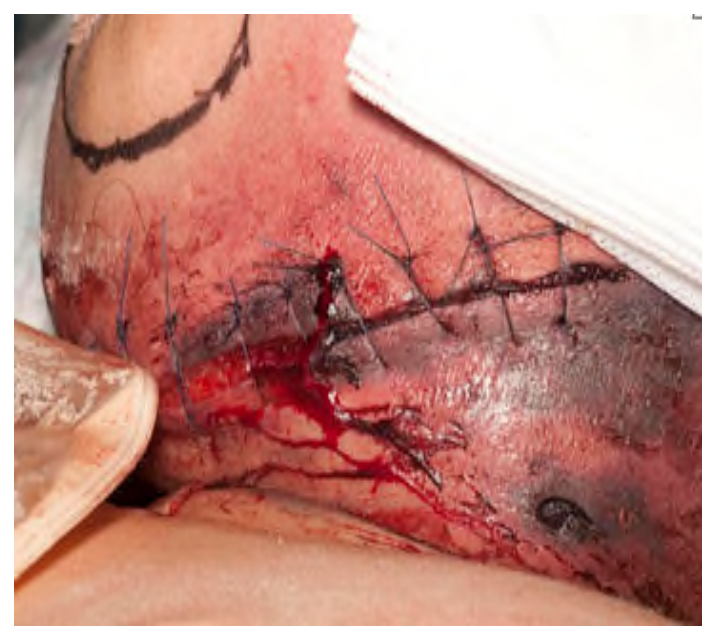


Figure 3. Case 7 presented with mouth ulcers (A) and pustular erythematous rash (B). Significant oral ulceration requiring hospital admission in case $6(C)$.

A

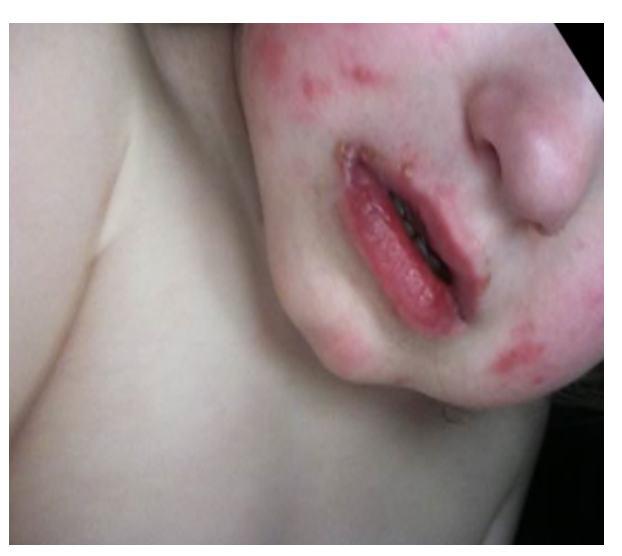

B

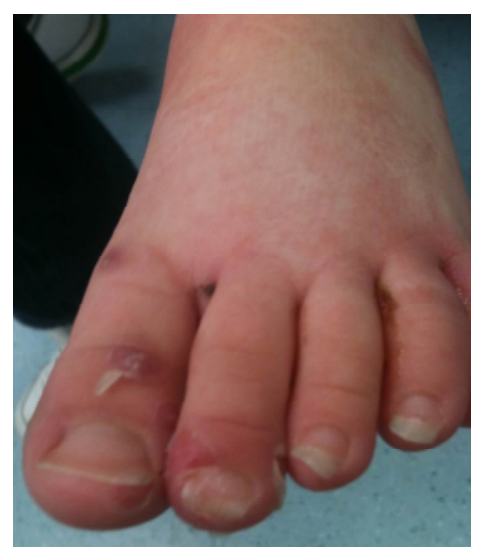

C

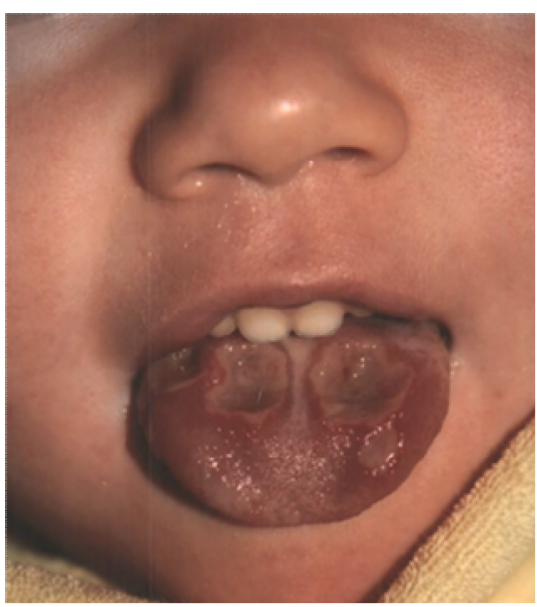


Figure 4. Unenhanced CT brain, coronal (A) and axial (B) reformats, shows hyperdensity and expansion of the superior sagittal sinus (dashed arrows) and emissary cortical veins (arrows), in keeping with venous thrombosis. MRI brain, coronal FLAIR (C) and axial T2 weighted imaging show bilateral brain infarctions in the parietal lobes.

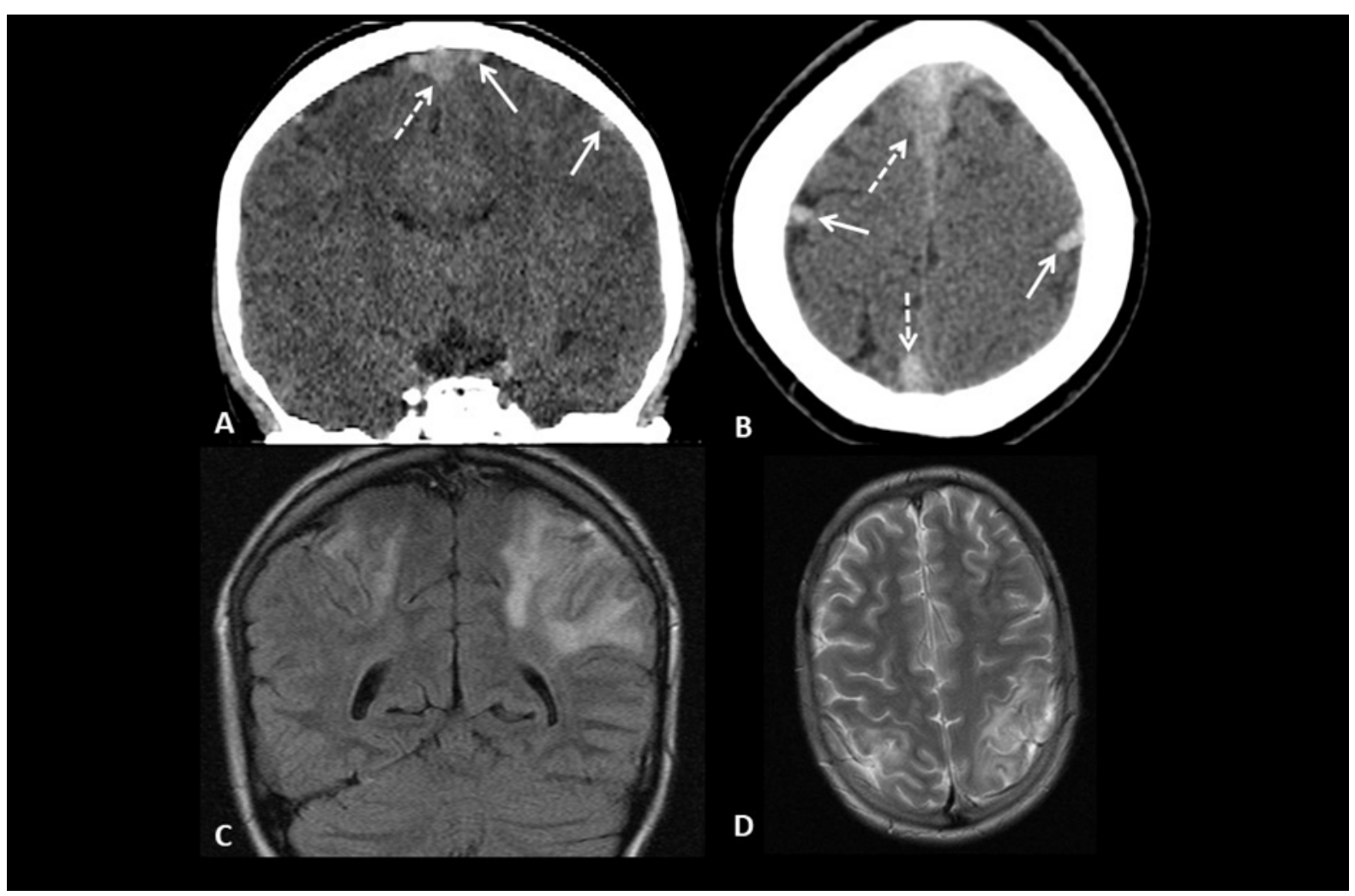

